\title{
Self-stigma in borderline personality disorder - cross-sectional comparison with schizophrenia spectrum disorder, major depressive disorder, and anxiety disorders
}

\author{
This article was published in the following Dove Press journal: \\ Neuropsychiatric Disease and Treatment \\ 22 September 2016 \\ Number of times this article has been viewed
}

\author{
Ales Grambal' \\ Jan Prasko' \\ Dana Kamaradova' \\ Klara Latalova' \\ Michaela Holubova ${ }^{1,2}$ \\ Marketa Marackova' \\ Marie Ociskova' \\ Milos Slepecky \\ 'Faculty of Medicine and Dentistry, \\ Department of Psychiatry, Palacky \\ University Olomouc, University \\ Hospital Olomouc, Olomouc, \\ ${ }^{2}$ Department of Psychiatry, Hospital \\ Liberec, Liberec, Czech Republic; \\ ${ }^{3}$ Faculty of Social Science and Health \\ Care, Department of Psychology \\ Sciences, Constantine the Philosopher \\ University, Nitra, Slovak Republic
}

\begin{abstract}
Introduction: Self-stigma arises from one's acceptance of societal prejudices and is common in psychiatric patients. This investigation compares the self-stigma of a sample of patients with borderline personality disorder (BPD), schizophrenia spectrum disorder (SCH), major depressive disorder (MDD), bipolar affective disorder (BAD), and anxiety disorders (AD) and explores of the self-stigma with the subjective and objective measures of the severity of the disorder and demographic factors.
\end{abstract}

Methods: The total of 184 inpatients admitted to the psychotherapeutic department diagnosed with $\mathrm{BPD}, \mathrm{SCH}, \mathrm{MDD}, \mathrm{BAP}$, and $\mathrm{AD}$ were compared on the internalized stigma of mental illness (ISMI) scale. The ISMI-total score was correlated with the subjective and objective evaluation of the disorder severity (clinical global impression), and clinical and demographic factors.

Results: The self-stigma levels were statistically significantly different among the diagnostic groups (BPD 71.15 \pm 14.74 ; SCH 63.2 \pm 13.27 ; MDD 64.09 \pm 12.2 ; BAD 62.0 \pm 14.21 ; AD 57.62 \pm 15.85 ; one-way analysis of variance: $F=8.698, d f=183 ; P<0.005$ ). However after applying the Bonferroni's multiple comparison test, the only significant difference was between the BPD patients and the patients with $\mathrm{AD}(P<0.001)$. Stepwise regression analysis showed that the strongest factors connected with the higher level of self-stigma were being without partner, the number of hospitalization, and the severity of the disorder.

Conclusion: The BPD patients suffer from a higher level of self-stigma compared to patients with $\mathrm{AD}$. In practice, it is necessary to address the reduction of self-stigma by using specific treatment strategies, such as cognitive therapy.

Keywords: self-stigma, borderline personality disorder, schizophrenia spectrum and related disorders, major depressive disorder, anxiety disorders, severity of the disorder

\section{Introduction}

Self-stigma is a maladaptive process in which individuals accept societal prejudices and integrate this evaluation into their self-concept. ${ }^{1}$ Persons suffering from psychiatric disorders may be principally vulnerable to the self-stigma. Self-stigmatization can be understood as a series of stages: $\left.{ }^{2} 1\right)$ persons becoming conscious of societal labels; 2) agree with the labels; 3 ) apply the labels to themselves; and 4) subsequently suffering lower self-esteem.

According to a meta-analysis by Livingston and Boyd, self-stigma is associated with the lower quality of life, levels of hope, self-esteem, self-efficacy, empowerment, social
Correspondence: Jan Prasko

Faculty of Medicine and Dentistry,

Department of Psychiatry, Palacky

University Olomouc, University Hospital

Olomouc, IP Pavlova 6, 77520 Olomouc,

Czech Republic

Tel +420588443519

Email praskojan@seznam.cz 
support, and higher severity of psychiatric symptomatology. ${ }^{1}$ Additionally, higher self-stigma is connected with lower functioning in social and work situations. ${ }^{3,4}$ Social maladaptation (especially social isolation) related to self-stigma results in further discrimination, which perpetuates a vicious circle of social stigma, self-stigma, and social maladaptation. ${ }^{5}$ Finally, self-stigma is correlated with the suicidality and with a history of suicide attempts. ${ }^{6,7}$ However, it is important to note, that associations between level of self-stigma and different variables are of correlational nature and thus do not indicate causal effects.

Patients with borderline personality disorder (BPD) expect and perceive social rejection stronger than the general population. ${ }^{8}$ They also show negative and unstable self- and other evaluations compared to healthy individuals. ${ }^{9,10}$ Both could be connected with higher level of self-stigma in this group of patients. Persistent problems in social interactions, as well as intense and unstable interpersonal relations, and exaggerated efforts to avoid abandonment describe core features of BPD. ${ }^{11-13}$ Studies report that individuals with a personality disorder, especially with BPD, stigmatize themselves more than persons without a personality disorder. ${ }^{14-17}$

The comprehensive model regarding how self-stigma affects function in patients with severe mental illness (SMI) was published by Yanos et al. ${ }^{18}$ It may be helpful also to the understanding of this process in BPD. By empirical data, they proposed two models. Consequences from model 1 reinforced the view that internalized stigma increase avoidant coping, active social avoidance, and depressive symptoms and that these interactions are intermediated by the influence of self-stigma on self-esteem and hope. Consequences from model 2 replicated relevant associations from model 1 but also reinforced the hypothesis that positive symptoms can affect hope and self-esteem. Conclusions from two models reinforced the assumption that self-stigma affects self-esteem and hope, leading to negative consequences associated with recovery. Global self-esteem among persons with SMI may be negatively affected by stigma or stereotyped beliefs about individuals with SMI. ${ }^{19}$ According to Lysaker et al, ${ }^{20}$ features of self-esteem related to lovability by others were closely connected with reduced feelings of being alienated from others due to psychiatric disorder. Features of self-esteem linked to the capability to manage one's businesses were more strictly related to the rejection of stereotypes of mental illness. A feeling of being capable of influencing others was related to both the absence of discrimination experiences and the ability to ward off the stigma. The possibility that internalized stigma and deficits in social cognition and metacognition in schizophrenia spectrum disorder ( $\mathrm{SCH}$ ) are risk factors for insight to convert to depression was tested by Lysaker et al. ${ }^{21}$ Patients with SCH with good insight and moderate depression reported more internalized stigma than those with poor insight and minimal depression. Patients with real insight and mild depression had higher levels of social cognition and metacognitive mastery than the other two groups.

While self-stigma is common in BPD, only a few studies have reported the investigation focusing on the comparison of the level of stigma in BDP patients with another diagnostic subgroup like psychosis, affective disorders or anxiety disorders (AD). Using the self-report questionnaires, Rüsch et $\mathrm{al}^{14}$ assessed the self-stigma in 60 females with BPD and 30 females with social phobia. Self-stigma was inversely related to the quality of life, self-efficacy, and self-esteem. Females with social phobia displayed lower self-stigma than females with BPD. This could reflect strong labeling processes as being mentally ill due to many interpersonal difficulties, repeated hospitalizations, and possibly visible scars. Ociskova et $\mathrm{al}^{16}$ showed that the average of internalized stigma of mental illness (ISMI) scale score was statistically higher in the patients with an anxiety disorder and a comorbid personality disorder compared to the patients without this comorbidity (especially in the ISMI subscales alienation and percieved discrimination).

The aim of our study was to investigate the self-stigma in patients with BPD and compare it with the self-stigma in patients with $\mathrm{SCH}$, major depressive disorder (MDD), $\mathrm{BAD}$, and $\mathrm{AD}$. The second aim was to study the relation between self-stigma, demographic characteristics, and the severity of the disorder. Understanding the relationship between self-stigma and clinical and demographic correlates may inform about interventions to reduce the self-stigma in high-risk subgroups. Being able to characterize a patient's self-stigma can help in treatment planning, which is reflected in the emerging literature on interventions to address self-stigma. ${ }^{1,4,22-24}$

We prepared several hypotheses before beginning of the study. They were:

(1) A self-stigma measured by ISMI-total score (TS) will be higher:

(a) in patients with BDP in comparison with patients with adjustment disorder;

(b) in patients in whom the problems started earlier in their life;

(c) in patients with higher level of psychopathology;

(d) in less educated patients;

(e) in patients with more psychiatric hospitalizations; 
(f) in patients without a partner;

(g) in patients without a job.

(2) The self-stigma of patients with BDP measured by ISMI-TS will be equal with the self-stigma of patients with $\mathrm{SCH}$, bipolar disorder, and MDD.

(3) The domain stigma resistance will be lower in patients with BDP than in other diagnostic groups.

\section{Methods}

Participants were recruited from outpatients of the Psychotherapeutic Psychiatric Department of University Hospital Olomouc in the period from July 1, 2014 to October 31, 2014. Then, the patients were screened for eligibility by the outpatient psychiatrists. The inclusion criteria were as follows:

(1) BPD, SCH, MDD, BAD, and AD according to International Classification of Diseases-10 research diagnostic criteria. $^{25}$

(2) the age of 18-60 years.

(3) both sexes.

Exclusion criteria included the inability to participate in psychiatric interviews or give informed consent, the age $<18$ or $>60$ years, being at immediate risk of suicide, actual or chronic serious somatic disorder, organic brain disease, and subnormal intelligence.

Including criteria were confirmed by the clinical interview of two experienced psychiatrists. The structured clinical interview, such as the severe combined immunodeficiency was not used. Patients who have comorbid investigated disorder, for example, comorbid BPD and MDD, was not excluded but received "the principal diagnosis" according to the psychiatrist, who recognize, which diagnosis had more severe expression at the time of evaluation.

\section{Description of the assessment tools} Internalized stigma of mental illness scale

The ISMI is a 29-item questionnaire which measures internalized stigma according to four-point Likert scale (strongly disagree, disagree, agree, or strongly agree). ${ }^{26}$ The total scale score ranges from 29 to 116 , with 63 and 64 being the average scores for self-stigma. The scale has five domains: alienation, stereotype endorsement, discrimination experience, social withdrawal, and stigma resistance. The alienation subscale assesses the patient's experiences of being less than a full member of or being disqualified from society due to his or her disorder. The stereotype endorsement subscale measures the degree to which the individual agrees with widely accepted stereotypes about people with mental illness. The perceived discrimination subscale is concerned with the patient's sensitivity to the way how other people treat him or her supposing they know about his or her mental illness. The social withdrawal scale was inspired by statements produced by focus group members who claimed that they avoid interactions with others not to burden them with their mental problems or because they fear rejection in case people around them learn about the mental illness. The stigma resistance subscale determines the degree to which the patient can be unaffected by self-stigma. ${ }^{26} \mathrm{~A}$ multinational study has tested the psychometric properties of the ISMI, finding an internal consistency reliability of $\alpha=0.90$ and a test-retest reliability of between 0.62 and $0.90 .{ }^{27}$ The Cronbach's alpha of the Czech translation of the scale $(\alpha=0.91)$ was excellent, as well as reliability analyzed by the split-half method (SpearmanBrown coefficient 0.93) and test-retest 3 weeks after the first measurement $(r=0.90, P<0.001){ }^{28}$

\section{Clinical global impression}

Clinical global impression (CGI) is a scale used for global assessment of the severity of psychopathology. ${ }^{29} \mathrm{We}$ used severity scale of CGI. It is one-item scale. The initial evaluation is performed by the patient's psychiatrist using the objective form of the scale (CGI-O). The patient also assesses himself/herself by the subjective version (CGI-S), which includes seven levels of severity of the psychopathology. The intra-class correlations lie in the interval 0.88-0.92. ${ }^{30}$

\section{The demographic questionnaire}

The demographic questionnaire contains basic information such as sex, age, the age of disease onset, marital status, living with partner or not, employment status, pension status, education, the number of psychiatric hospitalizations, and current medication.

\section{Treatments}

The antidepressant ( $\mathrm{n}=132 ; 71.7 \%$ ) were the most common drugs used by the participants, followed by antipsychotics $(n=83 ; 45.1 \%)$, tymostabilizers $(n=42 ; 22.8 \%)$, and anxiolytics ( $n=35 ; 19 \%)$. The dosage of medication was in ranges according to the guidelines of the therapy in treated diagnostic groups. The mean dosage of antidepressant was $40.92 \pm 26.89 \mathrm{mg}$ of paroxetine equivalent, in antipsychotics $4.49 \pm 13.14 \mathrm{mg}$ of risperidone equivalent, and $9.92 \pm 11.65 \mathrm{mg}$ of diazepam equivalent.

\section{Statistical analysis and ethics}

The packages GraphPad Prism version 5.0 (GraphPad Software, Inc., La Jolla, CA, USA) and the Statistical Package for the Social Science version 24.0 (IBM Corporation, Armonk, 
NY, USA) were used for statistical analyses. Descriptive statistics was applied to the demographic and clinical data. The Shapiro-Wilk $W$-test determined the Gaussian distribution of the demographic, clinical, and ISMI variables. The $t$-tests of the Mann-Whitney $U$-tests were used for comparison of the means. Mean ISMI, CGI-O, and CGI-S scores were calculated as were mean and standard deviation of each ISMI subscale. Differences between diagnostic groups were determined by unpaired $t$-tests and one-way analysis of variance. Associations between factors were analyzed by Pearson's or Spearman's correlations and multiple regression. The Fisher's exact test or chi-square test verified the connection between alternative variables (sex, marital status, partnership, education, and employment). Regression was conducted between ISMI (dependent variable) and demographic and clinical variables (independent variables) including diagnosis, age, sex, occupation, marital status, having or not having partner, rent, the age of the onset of the disorder, number of hospitalizations, years of education, degree of education, CGI-O, and CGI-S. The threshold for statistical significance was set at 5\%.

The ethic commitee of University Hospital in Olomouc approved the study. The investigation was conducted by the latest version of the Helsinki Declaration and standards of Good Clinical Practice. ${ }^{31}$ The patients signed informed consent.

\section{Results}

\section{Sample description}

The main characteristics of the sample are presented in Table 1. Diagnostic groups statistically significantly differ in most of the clinical and demographical parameters (Table 1). The "mean age" differs statistically significantly between diagnostic groups (see Table 1). The Bonferroni's multiple comparison tests showed that age of the patient with BPD is statistically significantly lower in comparison with ages of all other diagnostic groups (BPD vs SCH mean difference $($ diff $)=-7.52$, $t=3.06, P<0.05$; BPD vs MDD mean diff $=-15.54, t=5.76$, $P<0.001$; BPD vs BAD mean diff $=-9.80, t=3.54, P<0.01$; BPD vs AD mean diff $=-9.60, t=3.66, P<0.01)$.

The diagnostic groups had statistically significant differences in "male/female ratio" (Table 1) between diagnostic groups. Post hoc head-to-head analysis showed the statistically significant differences between BPD and SCH (Fisher's exact test: $P<0.0001$ ), BPD and MDD (Fisher's exact test: $P<0.01$ ), but not between BPD and BAD (Fisher's exact test: not significant [n.s.]), alternatively, BPD vs AD (Fisher's exact test: n.s.).

There were statistical differences in the "marital status" between the diagnostic groups (Table 1). Post hoc head-to-head comparisons showed the statistically significant differences between BPD and MDD (chi-square test: $P<0.005)$, BPD and BAD (chi-square test: $P<0.05$ ), BPD and AD (chi-square test: $P<0.05$ ), where more patients with BPD are single, but not between BPD and SCH (chi-square test: n.s.).

There was a significant difference between diagnostic groups in "partnership" (Table 1). The "length of the education" and "levels of education" (Table 2) differ significantly as well. The Bonferroni's multiple comparison tests showed that it is due to the differences in the degree of education between BPD vs BAD $(P<0.001)$, not due to comparison with other diagnostic groups.

There were statistically significant differences between the diagnostic group in the "onset of the diseases" (Table 1). The beginning of the psychiatric problems was recognized significantly at an earlier age in BPD patients in comparison with all other diagnostic groups (BPD vs $\mathrm{SCH}, P<0.05$; $\mathrm{BPD}$ vs $\mathrm{MDD}, P<0.001$; $\mathrm{BPD}$ vs $\mathrm{BAD}, P<0$; and $\mathrm{BPD}$ vs AD, $P<0.001)$.

Groups statistically significantly differ from each other in the "number of hospitalizations" in psychiatry (Table 1). When comparing the measurements using Dunn's multiple comparison test, there was shown that the difference is due to the dissimilarities between the BPD and MDD $(P<0.01)$, $\mathrm{BPD}$ and $\mathrm{AD}(P<0.001)$, and not with other diagnostic groups ( $\mathrm{SCH}, \mathrm{BAD})$.

\section{Severity of the disorder}

There was a statistically significant difference between diagnostic groups in "CGI-O" (Kruskal-Wallis statistic). The comparison between the groups for the severity of the disorder by using the Dunn's multiple comparison tests, showed that the differences between the BPD and all other diagnostic groups (Table 1). When comparing the scores in subjective "CGI-S", there was statistically significant difference between diagnostic groups also. According to the Dunn's multiple comparison tests, which compare each pair of the groups, the differences were found between BPD and $\mathrm{SCH}$, and BPD and BAD, not between other groups (Table 1).

\section{ISMI scores in different diagnostic groups}

The "ISMI-TS" was 63.51 \pm 14.57 . There was a high statistically significant difference among diagnostic groups according to the "ISMI-TS" (Table 1). When using the correction for multiple comparisons by Bonferroni's multiple comparison test, there were revealed differences between BPD patients and patients with AD. No other statistical differences between groups were detected in multiple comparisons. 
Table I Demographic and clinical data of the patients

\begin{tabular}{|c|c|c|c|c|c|c|c|}
\hline$\overline{\text { Categories }}$ & All & BPD & SCH & MDD & BAD & AD & $\begin{array}{l}\text { Statistics } \\
\text { (comparison diagnoses) }\end{array}$ \\
\hline Number (\%) & $184(100)$ & $35(19.0)$ & $49(26.6)$ & $33(17.9)$ & $30(16.3)$ & $37(20.1)$ & \\
\hline Age (year) (mean $\pm S D$ ) & $38.29 \pm 12.02$ & $29.97 \pm 9.64$ & $37.49 \pm 10.54$ & $45.52 \pm \mid 1.31$ & $39.77 \pm 11.91$ & $39.57 \pm 12.29$ & $\begin{array}{l}\text { One-way ANOVA: } \\
F=8.698, d f=\mid 83 ; P<0.0001\end{array}$ \\
\hline \multicolumn{8}{|l|}{$\operatorname{Sex}(n)$} \\
\hline Males & 83 & 7 & 32 & 18 & 12 & 14 & Chi-square test; $P<0.00$ I \\
\hline Females & 101 & 28 & 17 & 15 & 18 & 23 & \\
\hline \multicolumn{8}{|l|}{ Employment (n) } \\
\hline Yes & 84 & 8 & 18 & 18 & 16 & 23 & Chi-square test; $P<0.0 \mathrm{I}$ \\
\hline No & 100 & 27 & 31 & 15 & 14 & 14 & \\
\hline \multicolumn{8}{|l|}{ Marital status (n) } \\
\hline Single & 90 & 23 & 33 & 9 & 12 & 13 & Chi-square test; $P<0.005$ \\
\hline Married & 63 & 5 & 8 & 19 & 13 & 18 & \\
\hline Divorced & 27 & 6 & 7 & 5 & 3 & 6 & \\
\hline Widowed & 4 & I & I & 0 & 2 & 0 & \\
\hline \multicolumn{8}{|l|}{ Living with partner (n) } \\
\hline Yes & 85 & 16 & 12 & 21 & 18 & 28 & Chi-square test; $P<0.000$ I \\
\hline No & 95 & 39 & 37 & 12 & 12 & 9 & \\
\hline \multicolumn{8}{|l|}{ Rent (n) } \\
\hline No rent & 103 & 26 & 19 & 18 & 14 & 26 & Chi-square test; $P<0.000$ I \\
\hline Partial disability rent & 40 & 3 & 23 & 5 & 5 & 4 & \\
\hline Full disability rent & 30 & 6 & 7 & 6 & 7 & 4 & \\
\hline Old-age pension & 11 & 0 & 0 & 4 & 4 & 3 & \\
\hline \multicolumn{8}{|l|}{ Education (n) } \\
\hline Basic & 23 & 11 & 6 & I & I & 4 & Chi-square test; $P<0.000$ I \\
\hline Lower educational training & 41 & 4 & 9 & 14 & 2 & 12 & \\
\hline Secondary & 72 & 16 & 22 & 9 & 10 & 15 & \\
\hline University & 48 & 4 & 12 & 9 & 17 & 6 & \\
\hline $\begin{array}{l}\text { Years of education } \\
\text { (mean } \pm \text { SD) }\end{array}$ & $|3.58 \pm 2.9|$ & $12.20 \pm 2.75$ & $13.55 \pm 2.85$ & $13.82 \pm 2.70$ & $15.63 \pm 2.85$ & $|3.05 \pm 2.5|$ & $\begin{array}{l}\text { Kruskal-Wallis test: } 2 \mathrm{I} .18 \text {; } \\
P<0.00 \text { I }\end{array}$ \\
\hline $\begin{array}{l}\text { Onset of the disorder } \\
\text { (mean } \pm \text { SD) }\end{array}$ & $29.46 \pm 12.07$ & $19.03 \pm 5.98$ & $26.04 \pm 9.66$ & $35.67 \pm 13.83$ & $28.50 \pm 11.02$ & $33.03 \pm 11.70$ & $\begin{array}{l}\text { One-way ANOVA: } \\
F=|2.97, d f=| 83 ; P<0.0001\end{array}$ \\
\hline $\begin{array}{l}\text { Number of hospitalizations } \\
\text { (mean } \pm \text { SD) }\end{array}$ & $3.13 \pm 3.21$ & $5.67 \pm 4.72$ & $3.10 \pm 2.44$ & $1.8 \mathrm{I} \pm 2.40$ & $4.93 \pm 3.58$ & $0.73 \pm 0.93$ & $\begin{array}{l}\text { Kruskal-Wallis test: } 58.64 \text {; } \\
P<0.00 \text { I }\end{array}$ \\
\hline ISMI total score (mean $\pm S D$ ) & $63.5 I \pm 14.57$ & $71.15 \pm 14.74$ & $63.20 \pm 13.27$ & $64.09 \pm 12.20$ & $62.00 \pm|4.2|$ & $57.62 \pm 15.85$ & $\begin{array}{l}\text { One-way ANOVA: } \\
F=4.225, d f=183 ; P<0.005\end{array}$ \\
\hline Alienation (mean \pm SD) & $13.58 \pm 4.30$ & $|6.9| \pm 4.3 \mid$ & $12.76 \pm 3.92$ & $13.27 \pm 3.05$ & $12.80 \pm 4.12$ & $|2.5| \pm 4.54$ & $\begin{array}{l}\text { One-way ANOVA: } \\
F=7.316, d f=183 ; P<0.0001\end{array}$ \\
\hline $\begin{array}{l}\text { Stereotype endorsement } \\
\text { (mean } \pm \text { SD) }\end{array}$ & $13.65 \pm 3.52$ & $|4.46 \pm 3.8|$ & $13.76 \pm 3.30$ & $14.09 \pm 3.36$ & $13.27 \pm 3.48$ & $12.65 \pm 3.62$ & $\begin{array}{l}\text { One-way ANOVA: } \\
F=1.449, d f=183 ; \text { n.s. }\end{array}$ \\
\hline $\begin{array}{l}\text { Discrimination experience } \\
\text { (mean } \pm \mathrm{SD})\end{array}$ & $10.27 \pm 3.45$ & $11.88 \pm 3.37$ & $10.55 \pm 3.81$ & $9.78 \pm 2.69$ & $9.93 \pm 2.75$ & $9.14 \pm 3.70$ & $\begin{array}{l}\text { One-way ANOVA: } \\
F=3.334, d f=183 ; P<0.05\end{array}$ \\
\hline Social withdrawal (mean \pm SD) & $13.1 \mid \pm 4.03$ & $15.12 \pm 3.99$ & $12.84 \pm 3.92$ & $|3.2| \pm 3.23$ & $12.80 \pm 4.15$ & $11.78 \pm 4.27$ & $\begin{array}{l}\text { One-way ANOVA: } \\
F=3.379, d f=183 ; P<0.05\end{array}$ \\
\hline Stigma resistance $($ mean $\pm S D)$ & $12.64 \pm 2.88$ & $11.35 \pm 2.88$ & $|3.3| \pm 2.69$ & $13.73 \pm 2.45$ & $13.20 \pm 2.88$ & $11.54 \pm 2.83$ & $\begin{array}{l}\text { One-way ANOVA: } \\
F=5.674, d f=183 ; P<0.0005\end{array}$ \\
\hline $\mathrm{CGI}-\mathrm{O}($ mean $\pm \mathrm{SD})$ & $3.16 \pm 1.60$ & $4.57 \pm 1.50$ & $3.04 \pm 1.47$ & $3.27 \pm 1.44$ & $2.50 \pm 1.33$ & $2.4 I \pm 1.32$ & $\begin{array}{l}\text { Kruskal-Wallis test: } 40.4 \text { I; } \\
P<0.000 \text { I }\end{array}$ \\
\hline CGI-S (mean \pm SD) & $3.31 \pm 1.71$ & $4.29 \pm 1.43$ & $2.74 \pm 1.79$ & $3.73 \pm 1.74$ & $2.73 \pm 1.55$ & $3.24 \pm 1.50$ & $\begin{array}{l}\text { Kruskal-Wallis test: } 24.38 \text {; } \\
P<0.000 \text { I }\end{array}$ \\
\hline
\end{tabular}

Abbreviations: AD, anxiety disorder; ANOVA, analysis of variance; BAD, bipolar affective disorder; BPD, borderline personality disorder; CGI-O, clinical global impression objective; CGI-S, clinical global impression - subjective; $d f$, degrees of freedom; ISMI, internalized stigma of mental illness scale; MDD, major depressive disorder; $\mathrm{SCH}$, schizophrenia spectrum disorder.

The groups differ in particular between the ISMI subscale “alienation" (Table 1). The Bonferroni's multiple comparison tests demonstrated that it is due to the differences between $\mathrm{BPD}$ and $\mathrm{SCH}(P<0.001), \mathrm{MDD}(P<0.01), \mathrm{BAD}(P<0.001)$, and $\mathrm{AD}(P<0.001)$. The level of alienation is higher in $\mathrm{BPD}$ group than in all others.

The groups did not differ between the subscale "stereotype endorsement", but there was a significant difference in 
Table 2 Relationship between ISMI and demographic factors

\begin{tabular}{|c|c|c|}
\hline Demographic factors & $\begin{array}{l}\text { Correlation or } \\
\text { comparison of the } \\
\text { ISMI total score }\end{array}$ & Statistics \\
\hline Age (year) & Pearson $r=-0.05171$ & n.s. \\
\hline Age of the disorder onset & Spearman $r=-0.1701$ & $P<0.05$ \\
\hline Number of hospitalizations & Spearman $r=0.2399$ & $P<0.005$ \\
\hline Years of education & Spearman $r=-0.1625$ & $P<0.05$ \\
\hline CGI-O & Spearman $r=0.4216$ & $P<0.00$ I \\
\hline CGI-S & Spearman $r=0.4687$ & $P<0.00$ I \\
\hline Antidepressant index & Spearman $r=0.2105$ & $P<0.05$ \\
\hline Antipsychotics index & Spearman $r=-0.1059$ & n.s. \\
\hline Anxiolytics index & Spearman $r=0.0804$ & n.s. \\
\hline \multicolumn{3}{|l|}{ Sex $($ mean $\pm S D)$} \\
\hline Males & $62.42 \pm 14.01$ & Unpaired $t$-test: \\
\hline Females & $64.35 \pm 15.02$ & $t=0.8576, d f=|8|$; n.s. \\
\hline \multicolumn{3}{|l|}{ Employment (mean $\pm \mathrm{SD}$ ) } \\
\hline Yes & $58.69 \pm 13.79$ & Unpaired $t$-test: $t=4.272$, \\
\hline No & $67.52 \pm 14.04$ & $d f=|8| ; P<0.000 \mid$ \\
\hline \multicolumn{3}{|l|}{ Marital status (mean $\pm \mathrm{SD}$ ) } \\
\hline Single & $64.7 \mid \pm 14.18$ & One-way ANOVA: \\
\hline Married & $61.02 \pm 15.07$ & $F=I .46 \mid, d f=182 ;$ n.s. \\
\hline Divorced & $63.93 \pm 14.67$ & \\
\hline Widowed & $73.50 \pm 10.85$ & \\
\hline \multicolumn{3}{|l|}{ Partner (mean $\pm S D)$} \\
\hline Yes & $60.20 \pm 14.06$ & Unpaired $t$-test: $t=3.28$, \\
\hline No & $67.09 \pm 14.34$ & $d f=|8| ; P<0.005$ \\
\hline \multicolumn{3}{|l|}{ Benefits (mean $\pm S D$ ) } \\
\hline No rent & $61.07 \pm 15.18$ & One-way ANOVA: \\
\hline Partial disability rent & $66.70 \pm \mid 4.21$ & $F=2.412, d f=182 ;$ n.s. \\
\hline Full disability rent & $67.53 \pm 12.12$ & \\
\hline Old-age pension & $63.64 \pm 13.10$ & \\
\hline \multicolumn{3}{|l|}{ Education (mean $\pm S D$ ) } \\
\hline Basic school & $68.59 \pm 16.34$ & One-way ANOVA: \\
\hline $\begin{array}{l}\text { Lower vocational } \\
\text { training }\end{array}$ & $64.00 \pm I I .64$ & $F=1.962, d f=182 ;$ n.s. \\
\hline High school & $64.10 \pm 14.52$ & \\
\hline University & $59.90 \pm 15.58$ & \\
\hline
\end{tabular}

Abbreviations: ANOVA, analysis of variance; CGI-O, clinical global impression objective; CGI-S, clinical global impression - subjective; $d f$, degrees of freedom; ISMI, internalized stigma of mental illness scale; n.s, not significant.

subscale "discrimination experience" (Table 1). The difference reaches statistical significance in comparison of BPD and $\mathrm{AD}(P<0.01)$ but not in comparisons with other diagnostic groups (Bonferroni's multiple comparison tests: n.s.).

The comparison of ISMI subscale "social withdrawal" shows the statistically significant differences between diagnostic groups in one-way analysis of variance statistic $(F=3.379, d f=183 ; P<0.05)$. When the correction for the multiple comparisons using the Bonferroni's multiple comparison test was applied, statistically significant differences occurred only between BPD and AD patients $(P<0.01)$ but not in the comparisons with other diagnostic groups.

The last subscale of the ISMI is "stigma resistance". There were large statistically significant differences between diagnostic groups in stigma resistance $(F=5.674, d f=183$; $P<0.0005)$. In Bonferroni's multiple comparison tests were shown, that BPD group was different from $\mathrm{SCH}(P<0.05)$, MDD $(P<0.01)$, but not from BAD and AD.

\section{ISMI relationship with demographic and clinical variables}

ISMI-TS did not correlate with the age and sex, but it correlated significantly with the age of disease onset, the years of education, and number of hospitalizations (Table 2). There was strong statistical significant difference between employed and unemployed patients, while higher stigma, had patients with no job. There were no differences in mean self-stigma level between groups divided according to marital status, according to the presence of any retirement/pension or not, and the degree of education (Table 2). However, there was the strong statistically significant difference in ISMI-TS between patients with a partner and patients without a partner (Table 2).

There were statistically significant correlations among the ISMI-TS and CGI-S or CGI-O evaluation of the severity of the disorder and with an index of antidepressants (Table 2). There was also statistically significant correlation with the years of education (Spearman's $r=-0.1625, P<0.05$ ).

There was a significant correlation between mean antidepressant dosage (according to the index of the antidepressant), but not with an index of antipsychotic or anxiolytic dosage (Table 2).

\section{Multiple regression analysis of significant factors connected to the self-stigma}

Due to the several factors significantly related to the selfstigma, we decided to calculate a multiple regression analysis to find essential elements. The dependent variable was the ISMI-TS scale while CGI-O, CGI-S, the age of onset, diagnosis, years of education, partnership, number of hospitalizations, and employment were independent variables (see variables in Table 3). The method applied was a stepwise regression analysis. The resultant model explained $28.9 \%$ of the dependent variable. The strongest factors connected to self-stigma was being without partner, number of hospitalizations, and the severity of the disorder measured by CGI-O and CGI-S. 
Table 3 Multiple regression analysis with self-stigma as the dependent variable

\begin{tabular}{llllll}
\hline Regressor & B & SE & $\boldsymbol{\beta}$ & $\boldsymbol{t}$ & $\boldsymbol{P}$-value \\
\hline CGI-S & 2.960 & 0.671 & 0.345 & $4.4 I I$ & $<0.00 \mathrm{I}$ \\
Partnership & -5.444 & $\mathrm{I} .853$ & -0.187 & -2.938 & $<0.005$ \\
Number of hospitalizations & $0.73 \mathrm{I}$ & 0.296 & $0.16 \mathrm{I}$ & 2.469 & $<0.05$ \\
CGI-O & 1.478 & 0.746 & 0.160 & $1.98 \mathrm{I}$ & $<0.05$ \\
\hline
\end{tabular}

Note: Adjusted $r^{2}=0.289$.

Abbreviations: $B$, unstandardized coefficients $B ; \beta$, standardized coefficients beta; CGI-O, clinical global impression - objective; CGI-S, clinical global impression subjective; SE, standard error.

\section{Discussion}

There were statistically significant differences between diagnostic groups in the studied sample in many demographic features. With a focus on BPD, the patients with BPD were statistically significantly younger than patients with other diagnostic subgroups and their problems started earlier in the life. This result is in agreement with the diagnosis of personality disorder, the features and challenges of which are typically clearly recognizable in the adolescents. ${ }^{11,25}$

There were $80 \%$ of the BPD females in our sample which is in agreement with the previous finding according to which $75 \%$ of BPD patients are females. ${ }^{32}$ Only $14 \%$ of the patients with BPD were married (comparable with schizophrenic patients $-16 \%$ ), which is very low in comparison with the current average in the Czech Republic. Another $29.1 \%$ live with a partner; the percentage is comparable with a study of Skodol et $\mathrm{al}^{33}$ with $27 \%$ BPD patients living with a partner. Another explanation is the age - other diagnostic groups were significantly older than BPD patients.

There were $70 \%$ of unemployed BDP patients in our sample, which is more than ten times greater than the average unemployment rate in the Czech Republic. ${ }^{34}$ Borderline patients are unemployed in higher percentage above all other studied group of disorders. Unemployment rate corresponds to $69 \%$ of those found in other larger study. ${ }^{33}$ The level of unemployment in addition to personality disorder may also be related to a high proportion of patients who have only basic education (31\%).

Patients with BPD have been youngest, but nevertheless, they were hospitalized the most frequently from all diagnostic groups, comparable only with the patients with BAD. In contrast, comparable with $\mathrm{AD}$ patients, most patients with $\mathrm{BPD}$ have no rent, which can indirectly testify for underestimation of the suffering and difficulties associated with BPD by Czech committees for disabilities.

The ISMI-TS $63.51 \pm 14.57$ of the whole sample is comparable with the scores of other Czech studies with $\mathrm{SCH}_{2}, 35,36$ mixed
$\mathrm{AD},{ }^{16} \mathrm{MDD},{ }^{37} \mathrm{BAD},{ }^{38}$ or mixed diagnostic population. ${ }^{39}$ It is a medium-high self-stigma score close to the mean score for the patients' population evaluated for the standardization of the ISMI in mixed diagnosed Czech patients population. ${ }^{28}$ The mean scores of ISMI of our patients are also by the self-stigma studies in other countries. ${ }^{40}$ In our study, the level of self-stigma in patients with BPD was the highest of all compared diagnostic groups. Patients with BPD showed not only highest rate of overall self-stigma but also in all subscales of ISMI except stigma resistance.

Some personality factors, which characterize BPD, can be closely connected to self-stigma. Dominant sign of BPD is disturbances and uncertainty about self-concept, ${ }^{11,25}$ and patients with higher levels of self-stigma typically lose their former self-concept. ${ }^{41}$ BPD patients score highly on harm avoidance scales ${ }^{42}$ and this personality trait can increase the probability of development of self-stigma later in life. ${ }^{43}$ Self-directedness is reduced in BPD patients ${ }^{44}$ and this personality trait is also linked to self-stigma. ${ }^{43}$ Schema concept postulates the existence of maladaptive schemas, selfdefeating emotional and cognitive patterns established from childhood and repeated throughout life. ${ }^{45,46}$ Schemas in BPD have a similar content as the self-stigmatization assertions and beliefs, which are measured by the ISMI scale.

The objective CGI in BPD evaluated by outpatient psychiatrist show the statistically significant higher severity of the disorder in patients with BPD in comparison with the each of another diagnostic group.

Patients with BPD had the highest value of CGI-O of all researched disorders in our sample. The subjective CGI in BPD demonstrate the same: is greater in BPD patient than in other diagnostic groups. The results demonstrate the severity of the impact of BPD in the patient.

One of the results is that higher self-stigma in this diagnostic group is connected with younger age. However, as shown the correlation between ISMI and age, there was not signification relationship between the self-stigma and age in the whole sample. This finding is consistent with findings of Holubova et $\mathrm{al}^{36}$ in an outpatient population of patients with $\mathrm{SCH}$, with the results of Ociskova et $\mathrm{al}^{16}$ in $\mathrm{AD}$, and with results of Cinculova et $\mathrm{al}^{37}$ in patients with the MDD.

The findings indicated that ISMI-TS did not relate to age, sex, level of the education, supporting the results of the most studies of self-stigma, and demographic factors. ${ }^{16,36,47-50}$ This result does not correspond with the results of some other studies. In a study of Girma et $\mathrm{a}^{51}$ there was the significantly higher rate of ISMI-TS in females than in males and self-stigma decreased with increasing levels of education. 
On the other hand, Yen et $\mathrm{al}^{52}$ detected the relation among sex, age, and self-stigma. Mosanya et $\mathrm{al}^{53}$ found an inverse relationship between the level of education and degree of self-stigma. Different results of our study may be associated with the use of different scales to evaluate self-stigma, the different socioeconomic and cultural environment, or with the participation of other diagnostic groups of patients. By our findings is the review and meta-analysis of 127 articles dealing with stigma and self-stigma mainly in developed countries, which found no significant relationship between main demographic factors, such as age, sex, and education and the self-stigma. ${ }^{1}$

Unemployment was connected with higher level of selfstigma, what is similar as described by the study of EvansLacko et al. ${ }^{40}$ It seems that getting a job can be an important factor that could limit self-stigma. These findings highlight the importance of employment programs to improve the lives of people with mental disorders which also could reduce selfstigma. ${ }^{54}$ Multiple regression analysis of significant factors connected to the self-stigma showed a strong association with, being without partner, the severity of the disorder, and the number of previous hospitalizations.

Important factor linked to the self-stigma is a partnership, that is, patients with BPD, who have no partner significantly more self-stigmatized. It is impossible to determine the causality of this connection, but it can be assumed that patients who are more self-stigmatized also have difficulties with starting and maintaining the close relationship, the absence of a relationship then contributes to self-stigma.

Self-stigma was significantly positively associated with the CGI-S and CGI-O evaluations of a mental state, which may reflect the link between stigma and subjectively and objectively perceived differences between individuals from the norm in the severity of the disorder. ${ }^{1}$ Our results are consistent with Ocisková et al. ${ }^{28}$ The relationship between the number of previous hospitalizations and self-stigma could be given with a prerequisite for the patient and his close persons that patients with higher number of hospitalizations must be more seriously ill. Another possibility is that repeated hospitalization of BPD patients increases contact with the stigmatizing personnel and contribute to the internalization of stigma. ${ }^{55}$

Demographic data above shows how significant is disabling in various areas of life in patients with BPD. Also, this disability is relatively stable over time if symptoms of BPD are present. ${ }^{56}$ This information suggests the importance of finding an effective treatment for patients with BPD since the reduction of BPD symptoms could be followed by improvements in work and relationships. As we have described, job and partnership are also linked with the degree of self-stigma.
Another possibility is to focus the therapy directly to the self-stigma. Livingston and Boyd identified that stigma interventions are successfully reduced self-stigma in people with the various psychiatric disorder. One intervention involved Internet modules for psychoeducation and cognitive behavioral therapy (CBT), and the other group involved CBT sessions. ${ }^{1}$ Group intervention to help persons with SMI can reduce internalized stigma. ${ }^{57}$ Yanos et $\mathrm{al}^{22,23}$ and Roe et $\mathrm{al}^{24}$ developed narrative enhancement and cognitive therapy for helping SMI patients to recognize and deal with self-stigma. This approach may serve as an inspiration for the programs for fighting with self-stigma in BPD. Authors cultivated an intervention that would consist of not only psychoeducation materials about internalized stigma but also methods aimed at increasing the cognitive skills required for correcting dysfunctional cognitions which might impede the development of a different sense of self and positive identity.

\section{Limitations of the study}

Limitations of the investigation include not using the structured clinical interview such as the severe combined immunodeficiency, small sample size, the cross-sectional design; using a general objective evaluation scale, and the single-site setting.

\section{Conclusion}

The self-stigma has a strong psychosocial and psychiatric symptom connection, so it is recommended that clinicians discuss both societal stigma and self-stigma with patients and consider using strategies such as CBT to challenge the accuracy of patients' perceptions of the stigma. Adequate interventions that target to the self-stigma are essentially needed. Looking in the context that self-stigma is connected with the severity of the disorder, employment, and number of hospitalizations the appropriate therapy could specifically focus on these factors. Another investigation should evaluate self-stigma over the time of persons across the diagnostic disorder spectrum to inform about specific stigma decreasing activities.

\section{Acknowledgment}

This paper was supported by the research grants IGA MZ ČR NS 9752-3/2008.

\section{Disclosure}

The authors report no conflicts of interest in this work.

\section{References}

1. Livingston JD, Boyd JE. Correlates and consequences of internalized stigma for people living with mental illness: a systematic review and meta-analysis. Soc Sci Med. 2010;71(12):2150-2161. 
2. Corrigan PW, Rafacz J, Rush N. Examining a progressive model of selfstigma and its impact on people with serious mental illness. Psychiatry Res. 2011;189(3):339-343.

3. Alonso J, Buron A, Rojas-Farreras S, et al; ESEMeD/MHEDEA 2000 Investigators. Perceived stigma among individuals with common mental disorders. J Affect Disord. 2009;118(1-3):180-186.

4. Perlick DA, Rosenbeck RA, Clarkin JF, et al. Stigma as a barrier to recovery: adverse effects of perceived stigma on social adaptation of persons diagnosed with bipolar affective disorder. Psychiatr Serv. 2001; 52(12):1627-1632.

5. Latalova K, Ociskova M, Prasko J, Kamaradova D, Jelenova D, Sedlackova Z. Self-stigmatization in patients with bipolar disorder. Neuro Endocrinol Lett. 2013;34(4):265-272.

6. Latalova K, Prasko J, Kamaradova D, et al. Self-stigma and suicidality in patients with neurotic spectrum disorder - a cross sectional study. Neuro Endocrinol Lett. 2014;35(6):474-480.

7. Drapalski AL, Lucksted A, Perrin PB, et al. A model of internalized stigma and its effects on people with mental illness. Psychiatr Serv. 2013;64(3):264-269.

8. Winter D, Koplin K, Lis S. Can't stand the look in the mirror? Selfawareness avoidance in borderline personality disorder. Borderline Personal Disord Emot Dysregul. 2015;2:13.

9. Winter D, Koplin K, Schmahl C, Bohus M, Lis S. Evaluation and memory of social events in borderline personality disorder: effects of valence and self-referential context. Psychiatry Res. 2016;240:19-25.

10. Korn CW, La Rosée L, Heekeren HR, Roepke S. Social feedback processing in borderline personality disorder. Psychol Med. 2016;46(3): 575-587.

11. American Psychiatric Association. Diagnostic and Statistical Manual of Mental Disorders: DSM-5. 5th ed. Arlington, VA: American Psychiatric Association; 2013.

12. Lis $\mathrm{S}$, Bohus M. Social interaction in borderline personality disorder. Curr Psychiatry Rep. 2013;15(2):338.

13. Schmahl C, Herpertz S, Bertsch K, et al. Mechanisms of disturbed emotion processing and social interaction in borderline personality disorder: state of knowledge and research agenda of the German clinical research unit. Borderline Personal Disord Emot Dysregul. 2014;1(12):1-17.

14. Rüsch N, Hölzer A, Hermann C, et al. Self-stigma in women with borderline personality disorder and women with social phobia. J Nerv Ment Dis. 2006;194(10):766-773.

15. Sarısoy G, Kaçar ÖF, Pazvantoğlu O, et al. Internalized stigma and intimate relations in bipolar and schizophrenic patients: a comparative study. Compr Psychiatry. 2013;54(6):665-672.

16. Ociskova M, Prasko J, Kamaradova D. Relationship between personality and self-stigma in mixed neurotic spectrum and depressive disorders cross sectional study. Act Nerv Super Rediviva. 2015;57(1-2):22-29.

17. Ociskova M, Prasko J, Latalova K, Kamaradova D, Grambal A. Psychological factors and treatment effectiveness in resistant anxiety disorders in highly comorbid inpatients. Neuropsychiatr Dis Treat. 2016; 12:1539-1551.

18. Yanos PT, Roe D, Markus K, Lysaker PH. Pathways between internalized stigma and outcomes related to recovery in schizophrenia spectrum disorders. Psychiatr Serv. 2008;59(12):1437-1442.

19. Lysaker PH, Roe D, Yanos PT. Toward understanding the insight paradox: internalized stigma moderates the association between insight and social functioning, hope, and self-esteem among people with schizophrenia spectrum disorders. Schizophr Bull. 2007;33(1):192-199.

20. Lysaker PH, Tsai J, Yanos P, Roe D. Associations of multiple domains of self-esteem with four dimensions of stigma in schizophrenia. Schizophr Res. 2008;98(1-3):194-200.

21. Lysaker PH, Vohs J, Hasson-Ohayon I, Kukla M, Wierwille J, Dimaggio G. Depression and insight in schizophrenia: comparisons of levels of deficits in social cognition and metacognition and internalized stigma across three profiles. Schizophr Res. 2013;148(1-3):18-23.

22. Yanos PT, Roe D, Lysaker PH. Narrative enhancement and cognitive therapy: a new group-based treatment for internalized stigma among persons with severe mental illness. Int J Group Psychother. 2011; 61(4):577-595.
23. Yanos PT, Roe D, West ML, Smith SM, Lysaker PH. Group-based treatment for internalized stigma among persons with severe mental illness: findings from a randomized controlled trial. Psychol Serv. 2012; 9(3):248-258.

24. Roe D, Hasson-Ohayon I, Mashiach-Eizenberg M, Derhy O, Lysaker PH, Yanos PT. Narrative enhancement and cognitive therapy (NECT) effectiveness: a quasi-experimental study. J Clin Psychol. 2014;70(4): 303-312.

25. World Health Organisation. ICD-10 Classifications of Mental and Behavioural Disorder: Clinical Descriptions and Diagnostic Guidelines. Geneva, Switzerland: World Health Organisation. 1992.

26. Ritsher JB, Otilingam PG, Grajales M. Internalized stigma of mental illness: psychometric properties of a new measure. Psychiatry Res. 2003;121(1):31-49.

27. Chang CC, Wu TH, Chen CY, Wang JD, Lin CY. Psychometric evaluation of the internalized stigma of mental illness scale for patients with mental illnesses: measurement invariance across time. PLoS One. 2014;9(6):e98767.

28. Ocisková M, Praško J, Kamarádová D, et al. Self-stigma in psychiatric patients - standardization of the ISMI scale. Neuro Endocrinol Lett. 2014;35(7):624-632.

29. Guy W; National Institute of Mental Health (U.S.). Psychopharmacology Research Branch. Division of Extramural Research Programs, editors. ECDEU Assessment Manual for Psychopharmacology. Rockville, MD: U.S. Department of Health, Education, and Welfare, Public Health Service, Alcohol, Drug Abuse, and Mental Health Administration, National Institute of Mental Health, Psychopharmacology Research Branch, Division of Extramural Research Programs; 1976.

30. Kadouri A, Corruble E, Falissard B. The improved clinical global impression scale (ICGI): development and validation in depression. BMC Psychiatry. 2007;7:7.

31. EMEA, 2002. Available from: http://www.ema.europa.eu/docs/en_GB/ document_library/Scientific_guideline/2009/09/WC500003526.pdf. Accessed August 25, 2016.

32. Gunderson JG. Borderline Personality Disorder: A Clinical Guide. Washington, DC: American Psychiatric Publishing; 2001.

33. Skodol AE, Pagano ME, Bender DS, et al. Stability of functional impairment in patients with schizotypal, borderline, avoidant, or obsessivecompulsive personality disorder over two years. Psychol Med. 2005; 35(3):443-451.

34. Ministry of Labour and Social Affairs. Czech Republic unemployment rate; 2016. Available from: http://www.tradingeconomics.com/czechrepublic/unemployment-rate. Accessed August 25, 2016.

35. Vrbová K, Kamarádová D, Látalová K, et al. Self-stigma and adherence to medication in patients with psychotic disorders - cross-sectional study. Neuro Endocrinol Lett. 2014;35(7):645-652.

36. Holubova M, Prasko J, Latalova K, et al. Are self-stigma, quality of life, and clinical data interrelated in schizophrenia spectrum patients? A cross-sectional outpatient study. Patient Prefer Adherence. 2016;10: 265-274.

37. Cinculova A, Kamaradova D, Ociskova M, et al. Sebestigmatizace, adherence $\mathrm{k}$ léčbě a vysazování medikace u úzkostných poruch průřrezová studie [Self-stigma, treatment adherence, and medication discontinuation in anxiety disorders - a cross sectional study]. Ces slov Psychiat. 2015;111(1):7-13. Czech.

38. Hajda M, Kamaradova D, Latalova K, et al. Self-stigma, treatment adherence, and medication discontinuation in patients with bipolar disorders in remission - a cross sectional study. Act Nerv Super Rediviva. 2015; 57(1-2):6-11.

39. Kamaradova D, Latalova K, Prasko J, et al. Connection between selfstigma, adherence to treatment, and discontinuation of medication. Patient Prefer Adherence. 2016;10:1289-1298.

40. Evans-Lacko S, Brohan E, Mojtabai R, Thornicroft G. Association between public views of mental illness and self-stigma among individuals with mental illness in 14 European countries. Psychol Med. 2012;42(8): 1741-1752.

41. Corrigan PW, Watson AC. Understanding the impact of stigma on people with mental illness. World Psychiatry. 2002;1(1):16-20. 
42. Korner A, Gerull F, Stevenson J, Meares R. Harm avoidance, self-harm, psychic pain, and the borderline personality: life in a "haunted house." Compr Psychiatry. 2007;48:303-308.

43. Margetić BA, Jakovljević M, Ivanec D, Margetić B, Tošić G. Relations of internalized stigma with temperament and character in patients with schizophrenia. Compr Psychiatry. 2010;51:603-606.

44. Henry C, Mitropoulou V, New AS, Koenigsberg HW, Silverman J, Siever LJ. Affective instability and impulsivity in borderline personality and bipolar II disorders: similarities and differences. J Psychiatr Res. 2001;35:307-312.

45. Stein DJ, Young JE. Schema approach to personality disorders. In: Stein DJ, Young JE, editors. Cognitive Science and Clinical Disorders. San Diego, CA: Academic Press; 1992:271-288.

46. Young JE, Klosko JS, Weishaar ME. Schema Therapy: A Practitioner's Guide. New York/London: Guilford Press; 2003.

47. Ellison N, Mason O, Scior K. Bipolar disorder and stigma: a systematic review of the literature. J Affect Disord. 2013;151(3):805-820.

48. Karidi MV, Vassilopoulou D, Savvidou E, et al. Bipolar disorder and self-stigma: a comparison with schizophrenia. J Affect Disord. 2015; 184:209-215

49. Cerit C, Filizer A, Tural Ü, Tufan AE. Stigma: a core factor in predicting functioning in bipolar disorder. Compr Psychiatry. 2012;53(5): 484-489.

50. Lazowski L, Kollwe M, Stuart H, Milev R. Stigma and discrimination in people suffering with a mood disorder: a cross-sectional study. Depress Res Treat. 2012;2012:724848.
51. Girma E, Tesfaye M, Froeschl G, Möller-Leimkühler AM, Dehning S, Müller N. Facility based cross-sectional study of self stigma among people with mental illness: towards patient empowerment approach. Int J Ment Health Syst. 2013;7(1):21.

52. Yen CF, Chen CC, Lee Y, Tang TC, Yen JY, Ko CH. Self-stigma and its correlates among outpatients with depressive disorders. Psychiatr Serv. 2005;56(5):599-601.

53. Mosanya TJ, Adelufosi AO, Adebowale OT, Ogunwale A, Adebayo OK. Self-stigma, quality of life and schizophrenia: an outpatient clinic survey in Nigeria. Int J Soc Psychiatry. 2014;60(4):377-386.

54. Bond GR, Drake RE, Becker DR. An update on randomized controlled trials of evidence-based supported employment. Psychiatr Rehabil J. 2008;31(4):280-290.

55. Aviram RB, Brodsky BS, Stanley B. Borderline personality disorder, stigma, and treatment implications. Harv Rev Psychiatry. 2006;14(5): 249-256.

56. Skodol AE, Gunderson JG, McGlashan TH, et al. Functional impairment in patients with schizotypal, borderline, avoidant, or obsessive-compulsive personality disorder. Am J Psychiatry. 2011;159(2):276-283.

57. Lucksted A, Drapalski A, Calmes C, Forbes C, DeForge B, Boyd J. Ending self-stigma: pilot evaluation of a new intervention to reduce internalized stigma among people with mental illnesses. Psychiatr Rehabil J. 2011;35(1):51-54.
Neuropsychiatric Disease and Treatment

\section{Publish your work in this journal}

Neuropsychiatric Disease and Treatment is an international, peerreviewed journal of clinical therapeutics and pharmacology focusing on concise rapid reporting of clinical or pre-clinical studies on a range of neuropsychiatric and neurological disorders. This journal is indexed on PubMed Central, the 'PsycINFO' database and CAS,

\section{Dovepress}

and is the official journal of The International Neuropsychiatric Association (INA). The manuscript management system is completely online and includes a very quick and fair peer-review system, which is all easy to use. Visit http://www.dovepress.com/testimonials.php to read real quotes from published authors. 